\title{
DEMYSTIFYING THE IMPLEMENTATION OF FLEXIBLE LEARNING STRATEGIES ON INFORMATION SYSTEMS STUDENTS AMIDST THE GLOBAL PANDEMIC
}

\author{
Mark Van M. Buladaco, MIT \\ Institute of Information Technology, Institute of Computing, Panabo City
}

Article DOI: https://doi.org/10.36713/epra9031

DOI No: 10.36713/epra9031

\begin{abstract}
-
Many countries worldwide are affected, and there is a fear of losing this whole enduring semester or even more in the coming future. Flexible learning state of being in which learning and teaching are gradually autonomous since the boundaries of the time, place, and study pace are limited. The students enrolled within the Bachelor of Science in Information Systems (BSIS) program in Davao del Norte State College (DNSC) in the first semester of 2020-2021 are the main target of this study in how they follow and adapt the new-normal way of delivering instructional materials. This study used the quantitative approach under the descriptive research design method with the survey questionnaire as the primary data collection tool. Data gathering was done through the use of questionnaires in the form of an online survey.

The total population size of prospective respondents qualified in this study 226 students from Davao del Norte State College, Panabo City during the academic year 2020-2021 amid a pandemic enrolled in the program of BSIS. The coherent response to higher education dynamics, such as the need for technological innovation to adapt flexible learning. Relying on its resilient and innovative spirit, DNSC finds ways to continue delivering its essential new way of giving academic quality to the scholars. Flexible learning uses online and offline modalities and allows completion of scholars learning off-campus. Based on the findings, it can be assumed that the respondents, the Davao del Norte State College (DNSC), the current status of BSIS students are equipped with needed technologies and adjusted to flexible learning.
\end{abstract}

KEYWORDS: Flexible Learning, Global Pandemic, Information Systems, Davao del Norte State College,

Philippines.

\section{INTRODUCTION}

The fatal and infectious disease CoronaVirus, also known as COVID-19, has intensely affected the global economy. The COVID-19 pandemic outbreak forced many schools and colleges to stay closed temporarily. [1] Many countries worldwide are affected, and there is a fear of losing this whole enduring semester or even more in the coming future. The necessity to include e-learning as their flexible type to adjust the curriculum has made more projecting with the attack of the COVID-19. Flexible learning state of being in which learning and teaching are gradually autonomous since the boundaries of the time, place, and study pace are limited. The application of flexible learning techniques can happen at any course design; ideally, learning is modified besides metacognitive goals are pursued.

Furthermore, flexible learning is a set of educational systems concerned with improved choice, convenience, and personalization appropriate to the learner [2]. In particular, flexible learning provides learners with choices about where, when, and how learning occurs [3]. Independent learning is approached incrementally, with the final aim of establishing a comprehensive strategy and learner accountability, as well as preserving the frameworks that guarantee a high-quality learning experience. [4] conducted a multinational research and classified flexibility into five important categories: time, content, entrance criteria, educational method, resources, and delivery and logistics. 
There are aspects in a flexible learning environment; time place, learning will always be depending on its environment, content, it defines and motivates students. A study pointed out that although an increasing number of online tools are being used to enrich face-to-face learning, for a real blended learning setting, the online elements must be collected with each other in a purposeful manner [5].

Here in the Philippines, the government agencies, such as the Department of Education (DepEd) and the Commission on Higher Education (CHED), advocate online classes or flexible learning to address pandemic issues and the constraints executed on schools to follow health protocols and social distancing [6]. Thus, schools are now looking into the viability of implementing online classes or flexible learning, including online and offline courses. Subsequently, flexible learning gives students choices about when, where, and how they learn; this is often referred to as the pace, place, and learning mode [7]. Among numerous conditions for adult learners to control their learning, students' self-control of the time, sequence, and pace of learning remained recognized as the significant learning preferences wanted in higher education [8].

Like other higher learning institutions, Davao del Norte State College (DNSC) isn't immune from the consequences of this COVID 19 pandemic. COVID 19 is here, and nobody exactly knows when and the way it'll end. It's already brought suffering, disruption of normal life and business activities, disruption to how people think, do things, and define themselves. With the absence of preparation, COVID 19 brings DNSC to planning its teaching and learning process. The circumstances created by the current pandemic initiates DNSC to the new normal.

The scholars enrolled within the program of Bachelor of Science in Information Systems in Davao del Norte State College (DNSC) are the main target of this study in how they follow and adapt the new-normal way of delivering instructional materials. This can also assess to get this status of flexible learning systems as their new mode of delivery of learning interventions, the accessibility of internet and technologies, recognition of diverse learning styles, and behavioral control within the adaptable learning experience.

\section{Theoretical Framework}

This research is anchored on Zimmerman's self-regulated learning hypothesis, which is related to flexible education. Self-regulated learning theory "corresponds to autonomously produced thinking, feeling, and connecting in the context of personal objective adaptation" [9]. In the early stages of self-regulated learning, learners are responsible for task analysis, which is characterized as goal setting and strategic planning, as well as self-motivation, which is defined as "self-efficacy, result expectancies, intrinsic interest, and goal orientation." This idea is consistent with students engaged in flexible learning having the freedom to choose what, when, and how to learn. Additionally, flexible learning strengthens the self-regulated learning theory by allowing students to manage their own learning "Their goals and concepts are fixed, they have control over, and they respect their own process. The critical components of genuinely flexible education are "adaptability of learning to learners' needs in every situation" and the instructor's function as someone who "monitors, leads, and directs engagements toward the acquisition of knowledge, the expansion of competence, and self-improvement.

\section{Objectives of the study}

The objective of this study is to assess the current status of BS in Information Systems students on flexible learning implementation in Davao del Norte State College. This paper will also propose suggestions and recommendations for the success of flexible mode of learning of BS in Information Systems students during the situation of a global pandemic.

\section{Research Design}

\section{METHODOLOGY}

This study used the quantitative approach under the descriptive research design method with the survey questionnaire as the primary tool in the data collection. Descriptive research finds out prevailing conditions of facts in a group under study, and usually, variables or conditions studied are not controlled. This research design involves gathering data to test hypotheses or answer questions about the current status of the study's subject [10]. The selected research design has an empirical illustration structure with a subsequent theoretical analysis based on a survey conducted among Davao del Norte State College, specifically, Bachelor of Science in Information Systems (BSIS) students. Additionally, the judgment to take effect a quantitative approach under the descriptive research method comes from the fact that data in numerical character allows assessing students' current status in flexible learning amidst pandemic. Finally, the descriptive research method will provide a significant opportunity for 
potential researchers to compare results with previous findings and see if there is a consensus on this particular issue in the future.

\section{Research Locale}

The total population size of prospective respondents qualified in this study 226 students from Davao del Norte State College, Panabo City during the academic year 2020-2021 amid a pandemic enrolled in the program BS Information Systems (BSIS); this program has been recently a new course offered under the Institute of Information Technology. The BSIS student population is categorized into different year levels from 1st year to 3rd year, experiencing a flexible learning approach. They surveyed through an online questionnaire for their comfortable and ample vacant time that the respondent chooses to.

\section{Participants of the Study}

The study population was randomly surveyed from 1st year, 2nd year, and 3rd-year students in Davao del Norte State College. The study makes use of all the students that are officially enrolled in Bachelor of Science in Information Systems this regards to their characteristics such as age, gender, and year level and the means of their flexible learning capability and present current status in the new normal mode of delivering instructional materials also the accessibility of internet and technological means.

\section{Sampling Techniques}

The researcher chose quota sampling; it's an accurate technique for this study—also, the researcher choosing the respondents to have the same specific traits or qualities. Additionally, quota sampling is a non-probability sampling method in which researchers could create a sample concerning individuals representing a population.

\section{Statistical Treatments}

The data gathered from the questionnaire were collected and presented in tables and subjected to certain statistical treatments. The data were coded, tallied, and tabulated for better presentation and interpretation of the results. Appropriate statistical treatment using JASP is a free and open-source graphical program for statistical analysis designed to be easy to use and familiar to users. The statistical methods used by the researchers is the frequency and frequency distribution. Frequency tells how often something happens or occurs. The frequency of observation tells the number of times the observation occurs in the data. By counting frequencies, it can make a frequency distribution table that gives a snapshot of the data to find patterns. It's one way you can organize data so that it makes more sense.

\section{Data Collection Procedure}

Data gathering was done through the use of questionnaires in the form of an online survey. The survey mentioned above served as significant sources of information to answer the research problems. [11] Data is important for researchers to get while doing study. The term "data" refers to the many types of information that researchers collect on their subjects. As a result, data is regarded as the primary element that must be gathered prior to analysis. In keeping with the nature of the study, which is quantitative, the data utilized are numerical. The researchers began this study by first securing permission from the selected participants; the researchers gathered the respondents on the specific dates for conducting the survey. Research questionnaire forms were distributed through online channels such as Facebook groups, Facebook messenger, and email to the respondents to assess the current status of BSIS students on flexible learning in the time of pandemic while studying and coping with new learning environments. The study's significance and the directions answering the questionnaire and explained to the respondents before the administration of questionnaires.

\section{Research Instrument}

The study used Google forms as a source for obtaining the required data. This uses a standardized questionnaire. The online survey questionnaire incorporates the profile of the respondents and the questions on flexible learning. The online questionnaire is being channeled to the different platforms such as Facebook Group/Page and required a specific email to fill-up the questionnaire. 


\section{Ethical Considerations}

This study's core concerns are BSIS students in DNSC and their current status in the flexible learning approach of their education. Additionally, the researchers have to ensure their safety, give full protection so that they did not lose their trust, and also the researchers followed ethical standards in conducting this study as pointed by, these are the following: respect for persons, beneficence, justice, consent, and confidentiality [10]. An obligation of the researcher's respect for persons needs not to exploit the research participants' weakness. Self-sufficiency avoided maintaining the friendship, trust, and confidence among the participants and the researchers. Next, the researchers also require permission and approval from the selected college students who had been officially enrolled and belonged to the program. This is done to pay respect for the individuals concerned in the study. Another most important way of showing respect is consent to persons during the research. This is to let all participants become aware of the purpose and objectives of the research they are going to involve.

Additionally, the commitment of maximizing risks to the research requires beneficence participants instead of maximizing the profits that are due to them [11]. The anonymity of the participants keeps in order not to put each participant at risk. Participants were protected at all times, so every file of information was not left unattended or unprotected. Confidentiality towards the results and findings, including the participants' safeguard, the coding system is used. Meaning, the participants' identities were hidden; all materials answered questionnaires, encoded transcripts, notes, and others should be destroyed after the data were analyzed. Some of the participants were hesitant to be part of a survey at first because they were afraid of what to say but because of the researchers' reassurance to them regarding the confidentiality of the responses. The researchers will have to be extra careful with questions written in the questionnaires, and due respect will give importance to this study.

\section{RESULTS AND DISCUSSION}

The Bachelor of Science in Information Systems (BSIS) students of Davao del Norte State College responded to the college survey through online channels such as Facebook groups, Facebook messenger, and email. There are a total of 226 respondents from the BSIS program.

Table 1. Year Level Responses

\begin{tabular}{|l|l|}
\hline Year Level & Responses \\
\hline First Year & 124 \\
\hline Second Year & 79 \\
\hline Third Year & 23 \\
\hline
\end{tabular}

As shown in Table 1, several 226 participants engaged in responding to the survey among students who are enrolled in the BSIS Program. Most of the respondents were in year levels, 124 responses were 124 first-year students, and 79 responses were second-year students. Also, third-year comprises 23 responses.

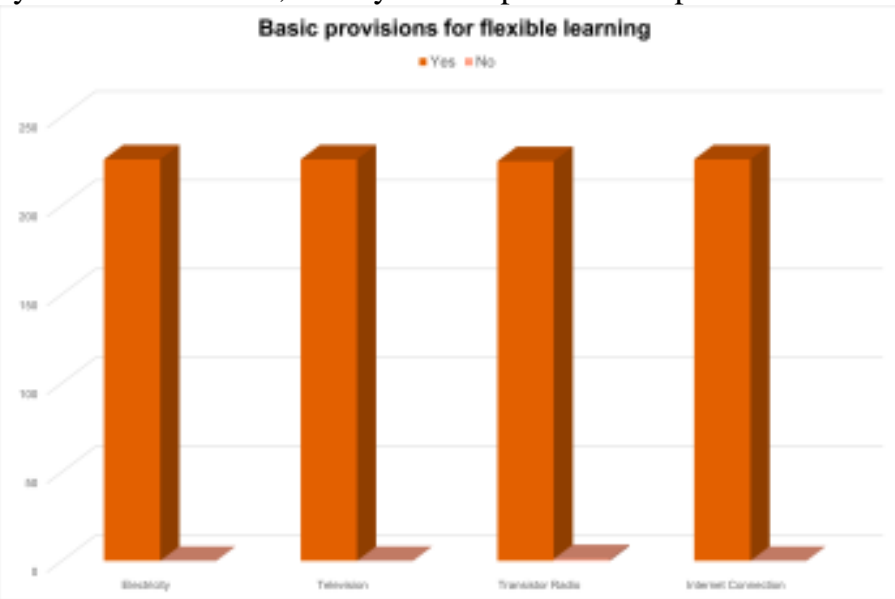

Fig. 1. Basic Provisions for Flexible Learning

Figure 1 shows that above states the basic provisions for flexible learning; it comprises the availability of them, such as electricity, television, transistor radio, and internet connection. In this case, most of the respondents have these basic provisions, almost 226 say "yes" that this necessity serves as the indicator on how they cope up with flexible 
learning and states in the results that most of the students have the necessity and the provisions to use and have the ability to adapt flexible learning. It was supported and explained that though most of the respondents have to connect to the internet, data show that most of the respondents used their devices for the tool for communication purposes only [12]. Only a few use their devices for the teaching and learning process.

Figure 2 shows the student's responses to their available type of internet connection in their homes to be used for flexible learning. The students can respond to multiple answers to this question. The prepaid/postpaid mobile data got the highest responses, 146, followed by Internet Cafe/PisoNet with 49 responses, and Home Fiber (PLDT, Globe, etc.) got 39 responses. Nevertheless, the overall type of internet connection presently is their home. According to a study, it stated that mobile devices and Wi-Fi providers have become more common; they also improved more widely included into students' lives, that this transition was prepared likely an increasing range of high-powered digital devices capable of connecting to the teaching space and the internet and by a new generation of students for whom constant connectivity is the norm [13].

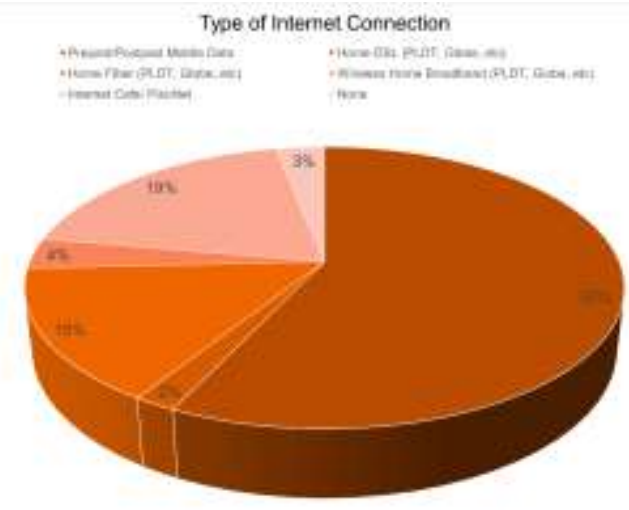

Fig. 2. Type of Internet Connection of the BSIS students for Flexible Learning

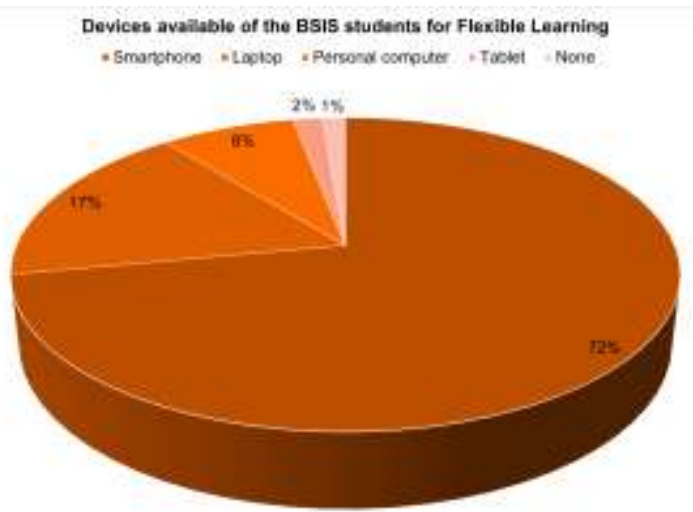

Fig. 3. Devices available of the BSIS students for Flexible Learning

Figure 3 shows the students' responses to their available devices in their homes to be used for flexible learning. The students can respond to multiple answers to this question. Based on their responses, the most common device is a smartphone (214), followed by a laptop with 51 responses, Personal Computer got 23 responses, and tablet got five responses. There are four responses of students' that don't have devices to use for flexible learning. Nonetheless, BSIS students' can manage and find ways to ensure that they are attached to the new normal mode of learning. Many students use these devices as part of their life, and it is one of the needs in flexibility learning. With this, it can be expected that most of the respondents can connect to the internet over their smartphones [14]. Also reinforced that smartphone or tablet can certainly enhance a student's online learning experience. 


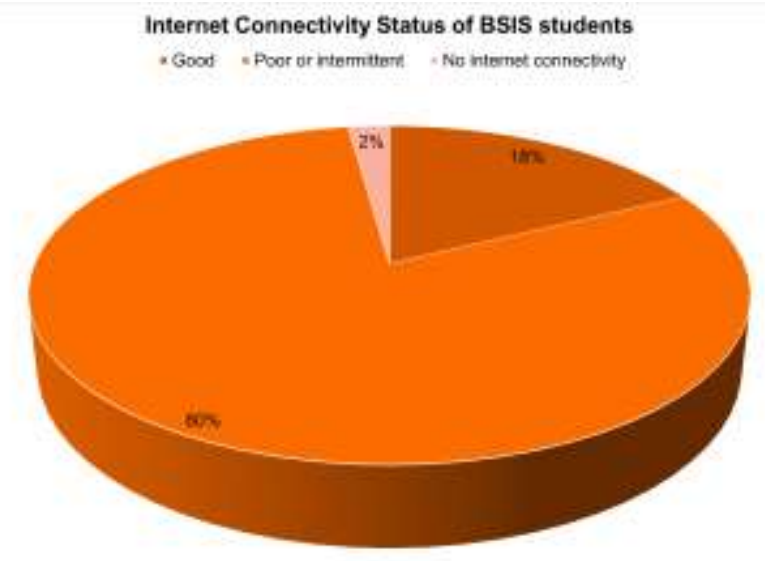

Fig. 4. Internet Connectivity Status of BSIS students

In figure 4, it presented the internet connectivity status of BSIS students. Since this versatile learning engages online type approach, there should be a web connectivity presence in their respective home to confirm that they will adjust the flexible learning. The table stipulated above that students mostly experiencing poor or intermittent connectivity aspiring to stay in terms of internet connection in their place. Their connection status is discontinuous; it makes it difficult for them to look for stable signals and connectivity. For a few reasons, others are good, and few scholars don't have internet connectivity. Internet connections must be good, where instant feedback from students may be achieved and might be used as another to face-to-face classes [15]. Adapting to a web teaching system under crisis is the biggest challenge for teaching and learning solutions, which will be made by the institutions to assist and cater to the pandemic [16].

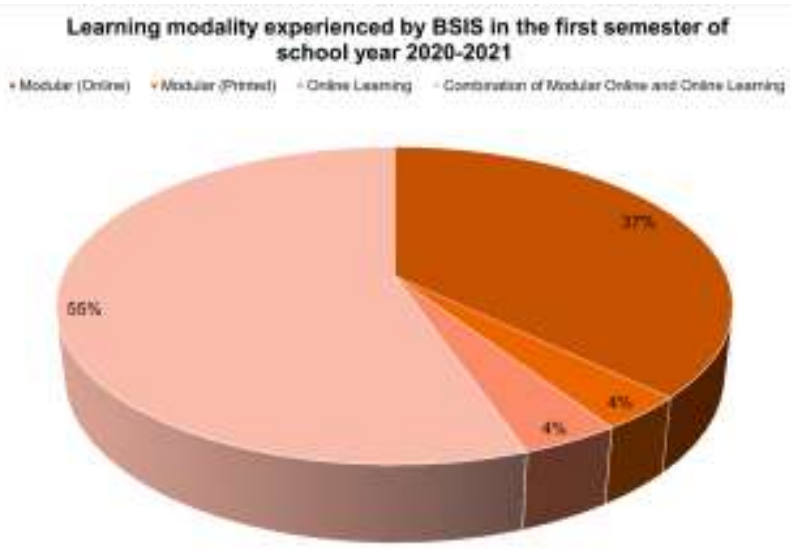

Fig. 5. Learning modality experienced by BSIS in the first semester of the school year 2020-2021

Figure 5 shows the learning modality experienced by BSIS students in the first semester of the school year 20202021, results state the combination of modular online and online learning got 125 responses is the most effective way of disseminating learning materials and conducting efficient mode of classes. It says that students are more comfortable than convenient in this kind of modality. Others stand for plain modular (online) with 84 responses and rarely for modular (printed) with eight responses and online learning. These flexible resources the students could access to the essential course resources [17]. It also sees that modular self-instruction materials will be helpful and are obtainable if students require them. 


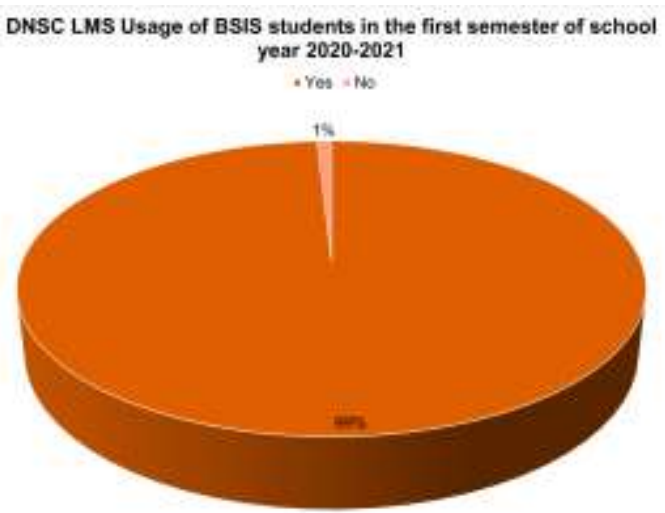

Fig. 6. DNSC LMS Usage of BSIS students in the first semester of the school year 2020-2021

Figures 6 shows the DNSC-LMS usage of BSIS students in the first semester of the school year 2020-2021, they respond that To cope up learning materials that can be used as the alternative way of learning such as modules, This system also shows that the responses below state that most of the BSIS students use DNSC LMS for their studies and enable them to update and complete course tasks. According to [18], teaching and learning through learning management systems (LMS) seems to be initially intended for distance education, which is affordable. That's why students don't seem to be familiar because the normal teaching approach is face-to-face modalities before the onset of technologies and online platforms.

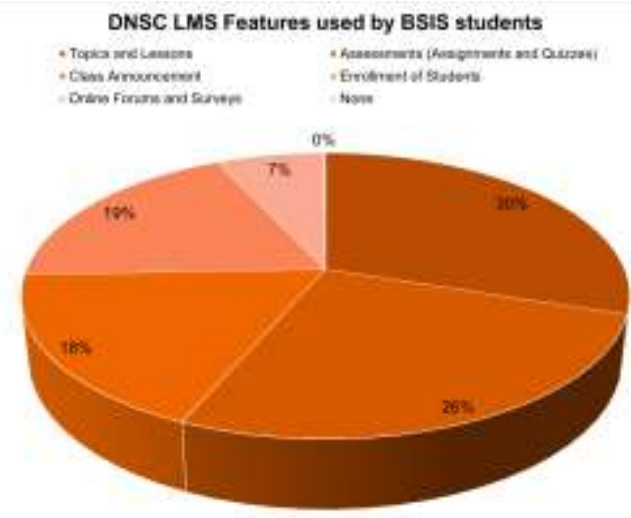

Fig. 7. DNSC LMS Features used by BSIS students

Figure 7 shows the results for Learning Management Systems features utilized by BSIS students. In this case, students could choose multiple answers. That topics and lessons got the highest response with 203, followed by assessments like giving assignments and quizzes with 179 responses, next enrollment status with 126 responses, also class announcement. The other's perspective is for online forums and surveys with 46 responses. DNSC management created a Learning Management System to guarantee that the students can have the topics and lessons to submit their tasks, assignments, and projects. 


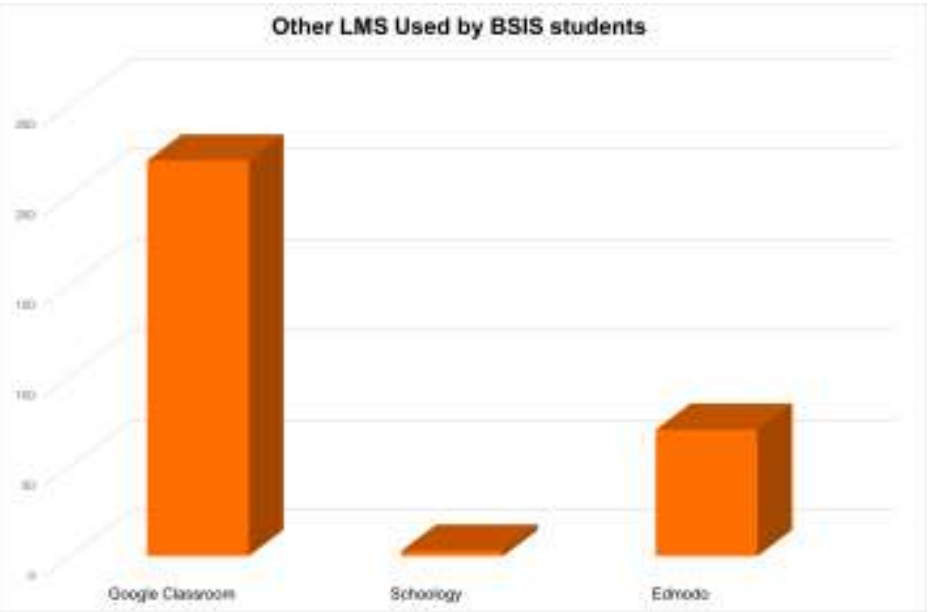

Fig. 8. Other LMS Used by BSIS students in the first semester of the school year 2020-2021

Figure 8 shows the results for other Learning Management Systems utilized by BSIS students. Google Classroom got 219, the best response among Schoology and Edmodo. This suggests that other than DNSC-LMS, there are other options that the instructors and professors manage classes for their students. According to Alharbi and Drew, teaching and learning through learning management systems (LMS) seems to be initially intended for distance education, which is affordable that's why students don't seem to be familiar because the normal approach of teaching is face to face modalities before the onset of technologies and online platforms [18].

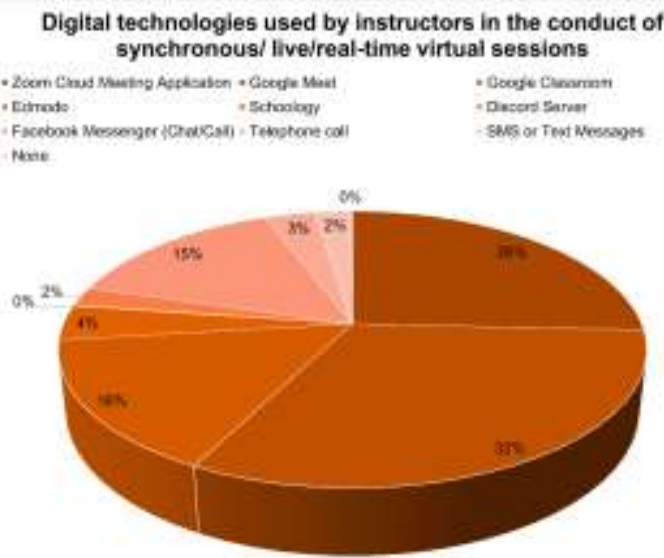

Fig. 9. Digital technologies used by instructors in the conduct of synchronous/live/real-time virtual sessions Figure 9 shows the digital technologies utilized by instructors within synchronous/ live/real-time virtual sessions. There are multiple responses of BSIS students, but mostly Google Meet is the most useful for synchronous learning with 219 responses followed by Zoom with 177 responses, google classroom is 107, responses and Facebook Messenger for chat or call is 101 responses, and a few responses to the remaining digital technologies. It signifies that flexible participation allows students to contribute to and get pleasure from classes in circumstances after they cannot attend face-to-face. Flexible participation options include online access to recorded lectures, participation grades earned via written comments rather than attendance, and live-streamed lectures with participatory components. Without a question, digital technology may improve learning by increasing access to knowledge, facilitating communication, and offering possibilities for self-directed and collaborative learning. ICT abilities may contribute to the development of competent, future-ready people [19]. The synchronous learning environment is organized in such a way that students attend live lectures, educators and learners engage in real time, and there is the possibility of immediate feedback [20]. 


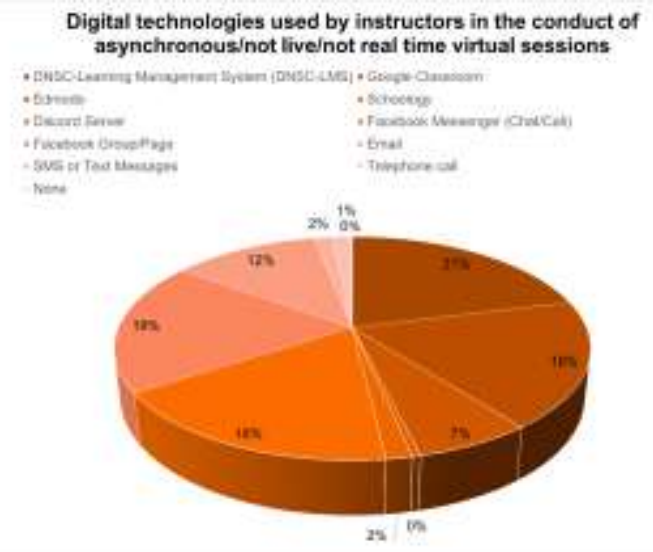

Fig. 10. Digital technologies used by instructors in the conduct of asynchronous/not live/not real-time virtual sessions

On the opposite hand, BSIS students' status on flexible learning in terms of digital technologies utilized by instructors within the conduct of asynchronous/not live/not real-time virtual sessions. BSIS students are most encountered in DNSC-LMS. This focuses on the parts of the tutorial process that instructors can control - meaning a spotlight on instructional approach and delivery. The very best response below shown in Table 11 garnering 165 to the Facebook Group/Page, next to it is Google Classroom 158 responses in keeping with instructors can create opportunities for flexible education in any of the areas for delivering information of proper platform of the place of study of off-campus, opportunities for contact with instructors and students through these sites, methods of support, and content delivery and communication channels. Additionally, asynchronous learning environments aren't properly structured. In such a learning environment, [21] learning content isn't available within the type of live lectures or classes; it's available at different learning systems and forums. Instant feedback and immediate response don't seem to be possible under such an environment. These results are also aligned with the assessment of Information Technology students in Davao del Norte State College [22].

\section{CONCLUSIONS}

The coherent response to higher education dynamics, such as the need for technological innovation to adapt flexible learning. Relying on its resilient and innovative spirit, DNSC finds ways to continue delivering its essential new way of giving academic quality to the scholars. Flexible learning uses online and offline modalities and allows completion of scholars learning off-campus. Based on the findings, it can be assumed that the respondents, the Davao del Norte State College (DNSC) the current status of Bachelor of Science in Information Systems (BSIS) students', equip and adjust on flexible learning, for the common of the respondents have technological means such as smartphones, laptops and can connect to the internet over mobile data and Wi-Fi providers. Since smartphones, laptops, and internet links are the technical requirements for online education for flexible learning and adapt to the synchronous and asynchronous learning approach. The result is incongruent to the Flexible pedagogies: Technology-enhanced learning by [7] states that innovations can be used to deliver learning in fully enhanced environments both online and blended. Besides, it helps students decide when to enter or exit a course and encourage them to work individually and attend online classes. Moreover, modular and online learning is the best approach for them to create participation and get instructional materials.

For the study's suggestion to the BSIS, learners (students), instructors, and institutions all have a role to play in facilitating flexible learning during a worldwide pandemic: Learners (students) must take responsibility for coping with and adapting to the new normal mode of providing education for their learning, seizing chances to selfadvocate for the mode of delivery that best meets their learning requirements. Second, teachers must be able to recognize possibilities for flexible learning, "with an increasing focus on managing the learning process rather than being the main supplier of instructional materials." Finally, institutions must design flexible systems that enable students to make informed decisions about their education and guarantee a high-quality learning experience. 


\section{ACKNOWLEDGMENTS}

The researcher would like to thank everyone who has contributed to the success of the study titled Assessment on the Current Status of BSIS Students on Flexible Learning amidst the Global Pandemic: A Case of Davao del Norte State College. The outcome of the job will be determined by the cooperation and efforts of many people. It won't be productive until we appreciate those who brought us to the information treasure. With sincere appreciation, I thank the Lord Almighty, who has been my source of strength and knowledge throughout our lives. The researchers thank the university and the BSIS students who actively participate in the online survey.

\section{REFERENCES}

1. Singh, V., \& Thurman, A. (2019). How many ways can we define online learning? A systematic literature review of definitions of online learning (1988-2018). American Journal of Distance Education, 33(4), 289-306

2. Shurville,S., O'Grady,T., and Mayall,P. (2008). Educational and institutional flexibility of Australian Educational Software. Campus-Wide Information Systems, Emerald Group Publishing Limited, 25 (2), 74 - 84.

3. Ryan, A. \& Tilbury, D. 2013. "Flexible Pedagogies: new pedagogical ideas." Higher Education Academy. https://www.heacademy.ac.uk/sites/default/files/resources/npi_report.pdf

4. Chen, D.-T. (2003). Uncovering the provisos behind flexible learning. Educational Technology \& Society, 6(2), 25-30.

5. Brown, M. G. (2016). Blended instructional practice: A review of the empirical literature on instructors' adoption and use of online tools in face-to-face teaching. The Internet and Higher Education, 31(Supplement C), 1-10. https://doi.org/10.1016/j.iheduc.2016.05.001

6. J. J. Joaquin, H. T. Biana, and M. A. Dacela, "The Philippine Higher Education Sector in the Time of COVID-19," Frontiers in Education, vol. 5, p. 208, Oct. 2020.

7. Gordon, N. 2014. Flexible Pedagogies: technology-enhanced learning. Higher Education Academy. https://www.heacademy.ac.uk/sites/default/files/resources/tel_report_0.pdf

8. Lin, B., \& Hsieh, C. (2001). Online teaching and learner control: a research review. Computers \& Education, $37,377-$ 386.

9. Bergamin, P. B., Werlen, E., Siegenthaler, E., \& Ziska, S. (2012). The relationship between flexible and self-regulated learning in open and distance universities. International Review of Research in Open and Distance Learning, 13(2), 101-123. Retrieved from http://ezproxy.lib.ryerson.ca/login?url=http://search.proquest.com/docview/1238190319?accountid=13631

10. Kothari, C.R. (2004) Research Methodology Methods and Techniques. 2Nd Edition, New Age International Publishers, New Delhi. - References - Scientific Research Publishing. [online] Available at: [Accessed 2 June 2020].

11. Creswell, J., W. (2006). Five Qualitative Approaches to Inquiry. SAGE Publications, Inc. Retrieved from Five http://www.sagepub.com/upmdata/13421_Chapter4.pdf

12. Sung, Y. T., Chang, K. E., \& Liu, T. C. (2016). The effects of integrating mobile devices with teaching and learning on students' learning performance: A meta-analysis and research synthesis. Computers \& Education, 94, 252-275. Retrieved on May 10, 2020 from https://bit.ly/3aJWCDy

13. Watkins, S. C., \& Cho, A. (2018). The digital edge: How Black and Latino youth navigate digital inequality (Vol. 4). NYU Press. Retrieved on May 10, 2020 from https://bit. ly/34MRqhk

14. Liguori, E.W.; Winkler, C. From offline to online: Challenges and opportunities for entrepreneurship education following the COVID-19 pandemic. Entrep. Educ. Pedagog. 2020. [CrossRef]

15. Basilaia, G.; Dgebuadze, M.; Kantaria, M.; Chokhonelidze, G. Replacing the classic learning form at universities as an immediate response to the COVID-19 virus infection in Georgia. Int. J. Res. Appl. Sci. Eng. Technol. 2020, 8, 101108. [CrossRef]

16. Sendelbah, A., Vehovar, V., Slavec, A., \& Petrovčič, A. (2016). Investigating respondent multitasking in web surveys using paradata. Computers in Human Behavior, 55, 777-787. Retrieved on May 10, 2020 from https://bit.ly/327ppOb

17. Palmer, S. R. (2011). The lived experience of flexible education--theory, policy and practice. Journal of University Teaching and Learning Practice, 8(3), 16. Retrieved from http://ezproxy.lib.ryerson.ca/login?url=http://search.proquest.com/docview/1011397499?accountid=13631

18. Alharbi, S., \& Drew, S. (2014). Using the technology acceptance model in understanding academics' behavioural intention to use learning management systems. International Journal of Advanced Computer Science and Applications, 5(1), 143-155. Retrieved on May 10, 2020 from https://bit.ly/2QCNlnm

19. Hyndman, B. (2018). Ten reasons why teachers can struggle to use technology in the classroom. Science Education News, 67(4), 41. Retrieved on May 10, 2020 from https://bit.ly/2ENWuqq

20. Singh, V., \& Thurman, A. (2019). How many ways can we define online learning? A systematic literature review of definitions of online learning (1988-2018). American Journal of Distance Education, 33(4), 289-306.

21. Littlefield, J. (2018). The difference between synchronous and asynchronous distance learning. https://www.thoughtco.com/synchronous-distance-learning-asynchronousdistance-learning-1097959. 
EPRA International Journal of Environmental Economics, Commerce and Educational Management Journal DOI: 10.36713/epra0414 |ISI I.F Value: 0.815|SJIF Impact Factor (2021): 7.743 ISSN: 2348 - 814X Volume: 8 | Issue: 12 | December 2021

22. Dabalos, J. T., \& Gameng, H. A. (2021). Making ends meet: A survey on adapting flexible learning amidst the COVID19 pandemic of the BSIT program in Davao del Norte State College. Turkish Journal of Computer and Mathematics Education (TURCOMAT), 12(3), 4735-4739. https://doi.org/10.17762/turcomat.v12i3.1896 